\title{
ESGE Newsletter
}

\section{Dear Friends and Colleagues,}

The European Society for Gynaecological Endoscopy (ESGE) will present in Athens its new organisation, which consists of three sections:

- the journal

- the European Academy, currently providing and organising the education in gynaecological surgery in Europe

- the Congress section, ensuring the continuity and standards for the scientific programme and the logistic organisation

This renewed organisation meets with the requests of our 26 national member societies to develop a dynamic European Society with major attention towards communication and education of the new gynaecological surgery.

The aims are to banish the politics and to take into account the reflections and echoes from the members, the involvement of young people and the integration of neglected countries. The ESGE should be a valuable (net)-

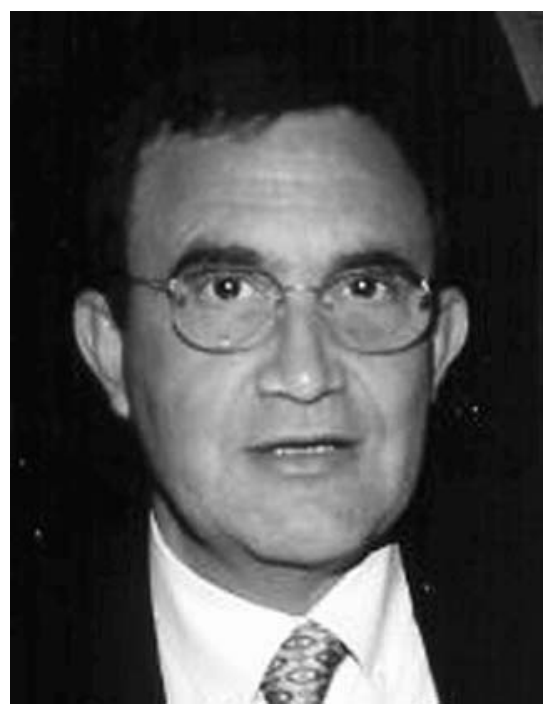
work instrument for all of us.

For the Athens Congress, we can count on the participation of the two national endoscopic societies, both active in training and education in modern surgery.

The above arguments, together with the quality and evaluation of the previous congresses, are the ingredients for the success of Athens 2005.

Being the originating country of the Olympic Games, country of culture and dynamism, Greece offers an exceptional location to host our congress. Besides the Mediterranean climate, Athens invites us to visit the numerous well-known sites such as the Acropolis, the ancient market, and the museums, as well as Piraeus, the port of Athens.

I hope this announcement will meet with your interest and will result in your participation.

Looking forward to welcoming you in Athens!

Best regards,

Professor J. Dequesne

ESGE President 


\section{The 14th Annual Congress of the European Society for Gynaecological Endoscopy(ESGE)}

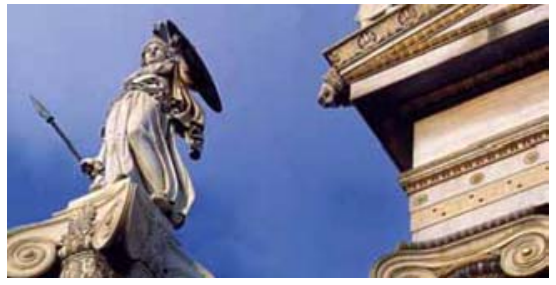

6-8 October 2005, Athens, Greece

Advanced Minimal Invasive Surgery in the Theatre and in the Office

Dear Colleagues,

On behalf of the organizing committee, we wish to extend a warm invitation to you to join us in October 2005.

We are honoured to host the 14th Annual Meeting of the European Society for Gynaecological Endoscopy (ESGE) in Athens. We are confident that this congress will appeal to the wide range of interests of our members and guests. In accordance with the previous annual meetings, the scientific programme will concentrate on new developments in various disciplines of gynaecological and endoscopic surgery. Special attention will be focused on newly conceived international techniques, along with other aspects of this minimally invasive surgery. In this way, workshops, plenary sessions, the "state of the art" lectures, symposia and poster discussions will provide the basis for scientific exchange on topics covered by the leading authorities in the field.

The Congress will be held in Athens, the host city of the 2004 Olympic Games, the metropolis of cultural history, with unique archaeological sites. An attractive social programme is planned for participants and accompanying persons, where they will get acquainted with our traditional warmth and hospitality.

\author{
M. Paschopoulos \\ President, Organizing Committee \\ G. Pados \\ General Secretary, Organizing Committee
}

\section{Q Hellenic Society of Operative Hysteroscopy and Laparoscopy in Gynaecology}

The society was established in 1990. Professor D.E. Lolis was elected President of the Society and he remained President until 2003, when he retired.

This society was the first endoscopic society in Greece and it is active throughout Greece. Up to now, the society has been organizing Pan-Hellenic Congresses of Endoscopy in Gynaecology every 2 years. Also, the society has organized three workshops on "Diagnostic and Operative Hysteroscopy" and one on "Transvaginal Endoscopy". All the workshops were under the auspices of ESGE.

President of the Society:

Professor E. Paraskevaidis (Ioannina)

Vice President:

Ass. Professor N. Dalkalitsis (Ioannina)

General Secretary:

Ass. Professor M. Paschopoulos (Ioannina)

Treasurer:

L. Papantonopoulos (Athens)

Members:

P. Stamatopoulos (Thessaloniki) G. Lialios (Larisa)

It was suggested by the society to the Ioannina Medical School to include the subject "endoscopy in gynaecology" as optional for the 5th year students. So, the subject has been taught from 1998 to the present.

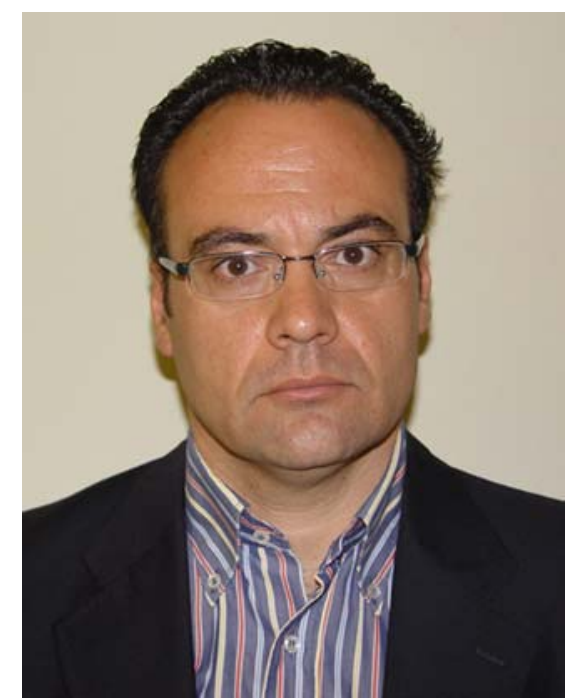

M. Paschopoulos

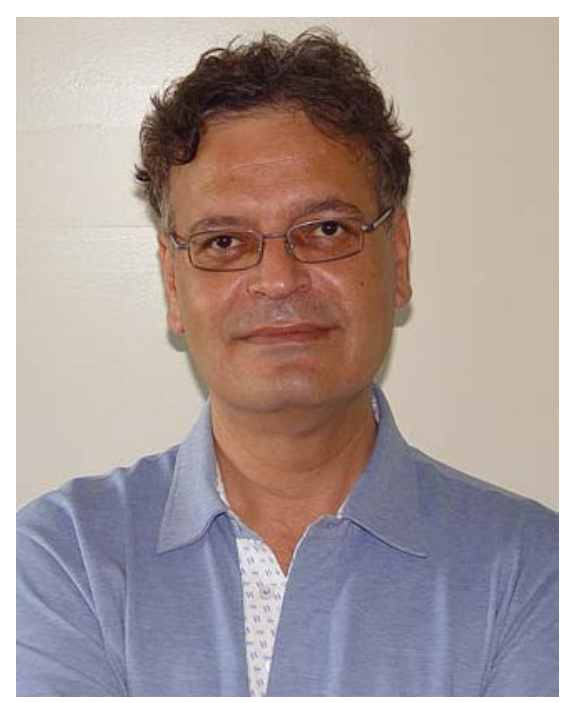

E. Paraskeviaidis 
The 14th Annual Congress of ESGE will be held (October 6-8, 2005), in Athens, in cooperation with the Hellenic Society of Gynaecological Endoscopy. The President of this Congress is M. Paschopoulos and the General Secretary is G. Pados.

Minas Paschopoulos,

Secretary of Hellenic Society of Operative Hysteroscopy and Laparoscopy in Gynaecology

\section{Interview of Professor Peter O'Donovan, Bradford, UK}

by Professor Neis, Saarbrücken

Dear Friend,

1. May I ask you at first to tell us some personal things:

- Where is your place of birth?

- Where did you grow up?

- Where did you study?

- Where did you start your education?

I was born in British Guiana, South America. My father was a member of the British Colonial Service working there. I spent my childhood in Cork, Southern Ireland, and attended Presentation Brothers College and Cork University there.

2. Which were the reasons for you to come to laparoscopy and hysteroscopy? And what did fascinate you especially about these techniques?

I started learning endoscopy in the late 1980s having trained in general and pelvic surgery. I attended workshops run by Bruno Van Herendal, Adam Magos, and Alan Gordon. I could see that it was the way forward and offered very good options as well as being requested by patients.

3. Where did you put the main focus on, in the clinical and scientific field?

I focus on mainly clinical and the scientific areas. I founded the MERIT Centre in Bradford in 1996.

4. Your mission has led you throughout the world. I am sure, you got to know lots of fascinating personalities.

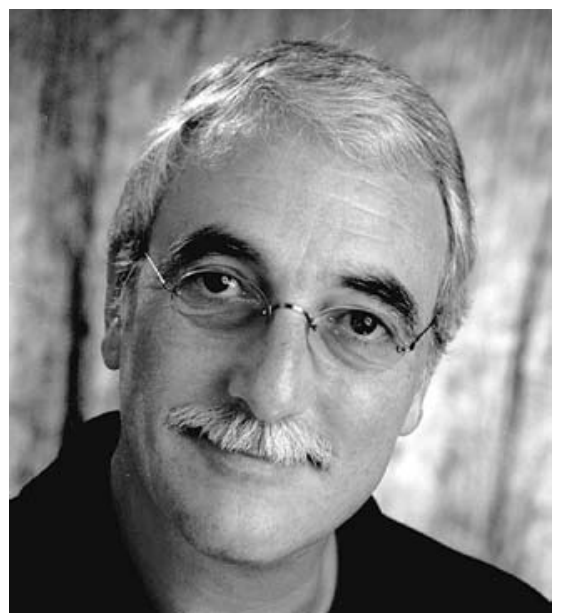

Klaus J. Neis
Who were the persons who impressed you the most and who maybe also took some influence on your way of life?

I have met many interesting people. The most impressive were as follows: Sir John Sulston, Nobel prize winner in medicine in 2002, who helped map the human genome; Prof. Alison Murdoch, pioneer in human cloning; Sir Alfred Cuschieri, who performed the first laparoscopic cholecystectomy; Prof. Kurt Semm, Prof. Bruhat and Mrs. Sybil Storz, who all helped promote endoscopic surgery globally. I also greatly admired Jay Cooper, who promoted ambulatory surgery in the USA.

5. In Great Britain you are a very active endoscopist. In your opinion: what is the status of operative hysteroscopy and laparoscopy in Great Britain? Is it daily routine or are there only some specialists offering these techniques locally?

Endoscopic surgery in the field of gynaecology is still being developed in the UK. The British Society of Gynaecological Endoscopy is very active in promoting, training and educational initiatives. Alan Gordon, Ray Garry, Christopher Sutton and Adam Magos were pioneers in the UK in the teaching of endoscopic surgery. The current president of the BSGE, Jeremy Wright, is highly productive in the development of laparoscopic surgery. Both Sian Jones and I are developing operative hysteroscopic training in the UK with the help of the RCOG and BSGE.

6. You are working at the Bradford Teaching Hospitals. Would you please tell us something about your work and activities there?

I am currently consultant gynaecologist and Director of Medical Innovation at Bradford Teaching Hospitals a large teaching hospital of over 1000 beds based in the North of England. I am also Professor of Medical Innovation at Bradford University. I have acted as an advisor to the Department of Health since 2000.

7. You are the editor of 'Gynaecological Surgery': What is the status of the journal today; what are you planning for its future?

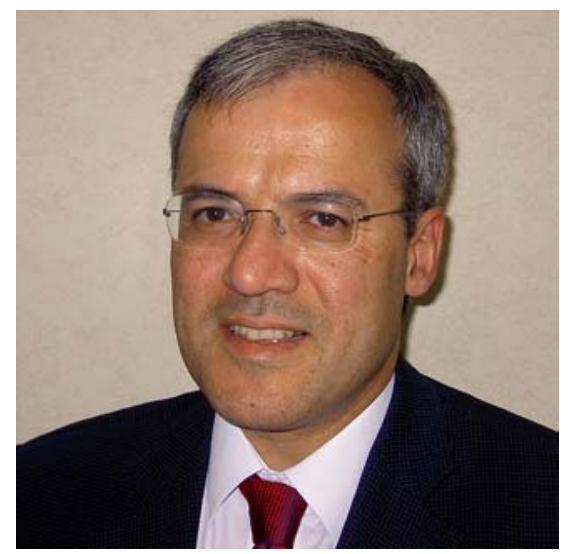

Peter O'Donovan 
Gynaecological Surgery is a new journal and I am honoured to be the first editor. It is gaining a very good reputation and attracting numerous papers. I would like it to become a "must read" journal in this field. It is currently distributed to all members of the European Society of Gynaecological Endoscopy in almost 30 countries. The next editor, Prof. Wallwiener, is likely to develop the journal's reputation further.

8. As I know, you are living within a family with four children. Your hospital, the research, the teaching and the family - is there still time for hobbies?

My main hobbies include travelling, reading, playing tennis, watching rugby, and playing football with my two sons. My ultimate ambition is to score a winning world cup goal, preferably against Germany, in 2008! I suppose I could be described as an eternal optimist.

Professor O'Donovan, we thank you very much for this interview and wish you all the best for the future.

\section{In memoriam - Daniel Dargent}

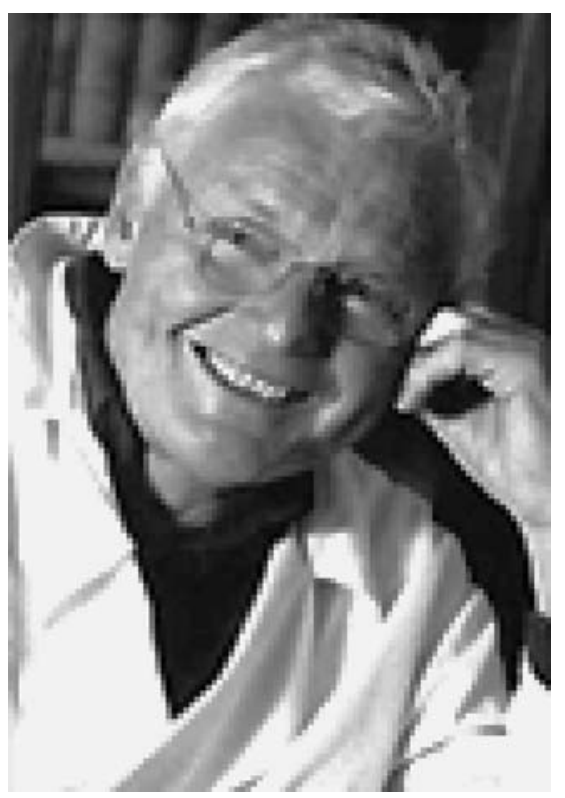

Daniel Dargent died recently. After fighting all his life against his patients'cancer, he lost his last battle.

I was with him when he discovered his disease and was impressed by his lucidity. He was aware of his disease, the poor prognosis and the magnitude of the treatment, but he nevertheless always retained hope of winning and continued on working, teaching and inventing until the end.

I was one of his friends. His knowledge impressed me very much, like everyone else. But most of all, I loved his sense of humanity.

Shortly before his death, I invited him to participate in a gynecological course organized in Strasbourg during which he made the following reflexion: "The surgical part of the treatment of cancer is a drop in the ocean: one who is not able to spend time with patients, to listen to them, to be nearby when they need it, cannot be an oncological gynecologist".

He had a great opinion of our profession and fought all his life for the recognition of gynecological surgery. He was respected by the whole surgical community: his knowledge was tremendous and outstanding. This knowledge was the result of a huge amount of work and I was always impressed seeing him going early to his hotel room to prepare his talks for the next day. Although he knew his lectures by heart, he continuously kept on adding information and/or challenging new ideas.

No-one who did not operate with Daniel can understand what surgery meant for him. Surgery was for him an intellectual act, a challenge of intelligence, the final step of a brilliant strategy to win against the disease. In one word: surgery was an art, and like in art, some works are fascinating and stay in people's mind as a major contribution. Daniel Dargent's surgery we will remember for ever.

When he learnt the vaginal route, he immediately understood its merits and possibilities, but was also open to new techniques and participated into the development of endoscopy, inventing the retroperitoneal route for lymphadenectomy.

We challenged ideas together during the past 15 years, and even if we did not always agree, our discussions were fruitful and enabled us to developed many new ideas. His main piece of work is probably the radical trachelectomy, and as D. Queleu suggested, we should call it "Dargent's operation".

More recently, he introduced the concept of the sentinel node in pelvic cancer. As usual, he went from the concept to the technique, from the technique to the evaluation and from this evaluation he published his results and made numerous communications at international congresses. The sentinel node is a good example to demonstrate Daniel's numerous qualities. Like all inventors in front of a new idea, he was very excited and strongly stood up for his concept, but when the results of the evaluation were not as good as expected, he immediately published them and tried to understand where the weak point was.

Daniel Dargent was a good, creative, innovative and honest surgeon. In him we have probably lost one of our most knowledgeable colleagues. I realize now what we have lost by not having learnt enough from him.

The European Society of Gynecological Endoscopy's Executive Board, Board and Members would like to offer their condolences to his spouse Brigitte and to his whole family.

Goodbye, Monsieur le Professeur.

A. Wattiez 


\section{The Spirit of the ESGE: Educational Grant 2002}

One of the important objectives of European Society for Gynaecological Endoscopy (ESGE) is to broaden the education in gynaecological endoscopy and establish standards of training. With the acceptance of the ESGE educational grant for 2002 an enormous opportunity has been offered to me to improve myself in gynaecological endoscopic techniques and to establish connections with my colleagues abroad, and I decided to use that opportunity as much as I could. But also a huge responsibility has been given to me to transfer later my new knowledge and skills to my colleagues and work in future in the spirit of the grant.

Between April and June 2003 I learned from and worked with such great endoscopists and teachers as Dr. Kees Wamsteker and Dr. Mark Hans Emanuel from Spaarne Ziekenhuis in Haarlem and Dr. Sjord de Blok and Dr. Erica Bakkum from Onze Lieve Vrouwe Gasthuis in Amsterdam, the Netherlands. The highlight of my stay in the Netherlands has been the outpatient hysteroscopy, and in July 2003 I managed to transfer and organise our outpatient hysteroscopy office in the Department of Gynaecology and Obstetrics in the University Hospital of Maribor. With a very successful donation campaign we purchased all the necessary equipment for it. In accordance to my promise that I will

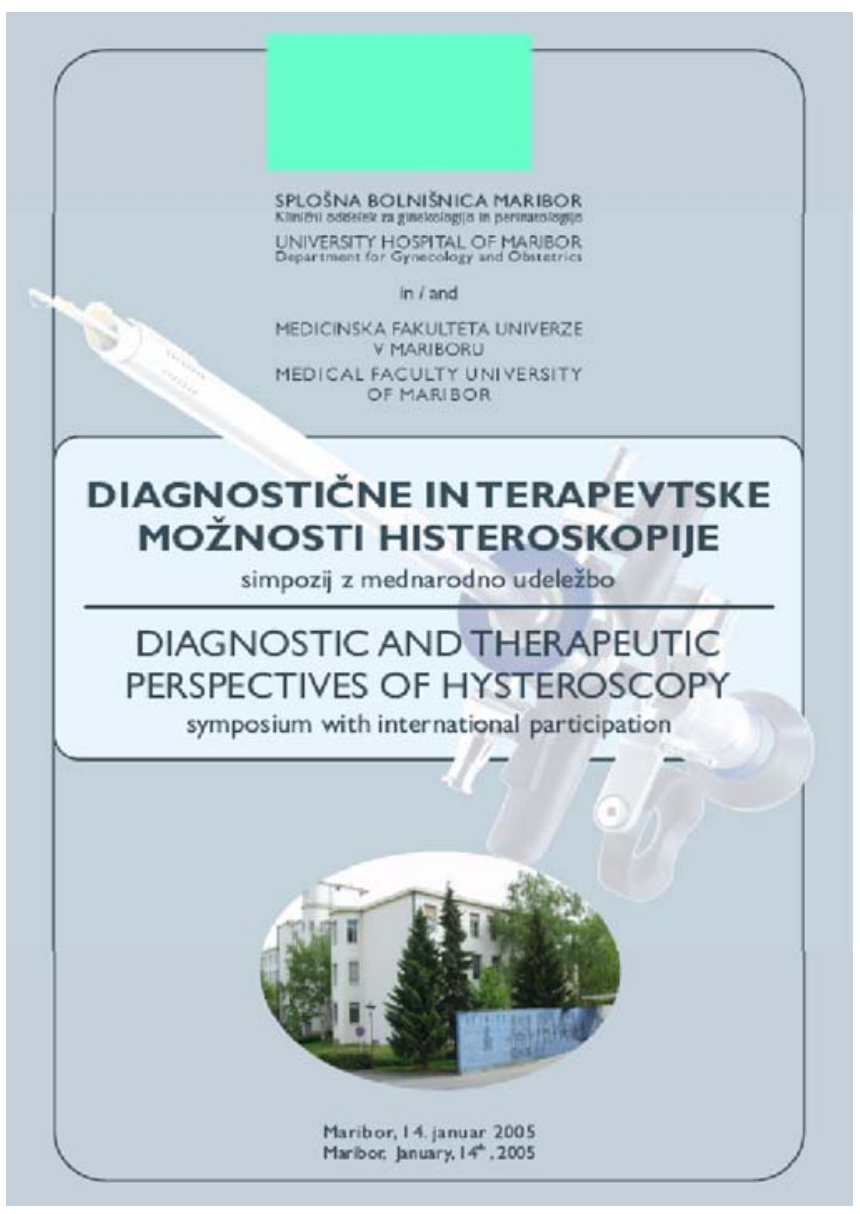

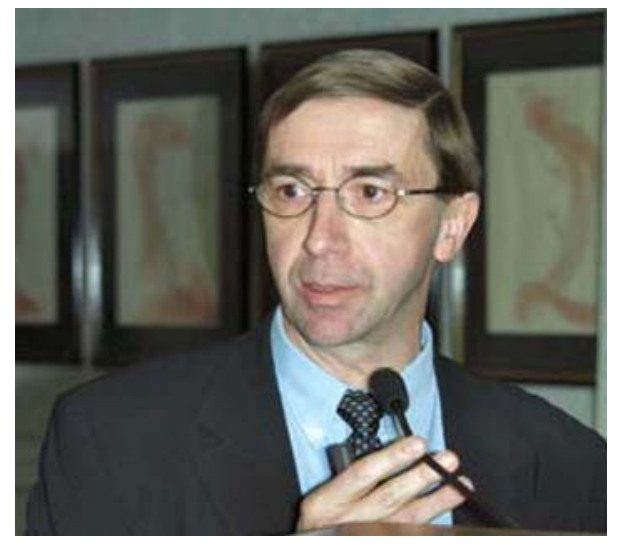

Yves van Belle

transfer my knowledge to my colleagues and to promote the outpatient hysteroscopy in Slovenia, my department, together with the Medical Faculty, University of Maribor, organised a one-day symposium with international participation and with a published abstracts book. The symposium, called "Diagnostic and Therapeutic Perspectives of Hysteroscopy", was held on 14 January 2005 in Maribor. The interest in our topics was enormous: we had 113 participants, not only from Slovenia, but also from Croatia, Italy, Bosnia, and Serbia and Montenegro.

The symposium was opened with an excellent talk by Dr. Yves Van Belle of Belgium about the possibilities, limits and challenges of modern hysteroscopy. The presence of Dr. Van Belle, who is the ESGE chairman for hysteroscopy, gave our symposium a broader aspect. In
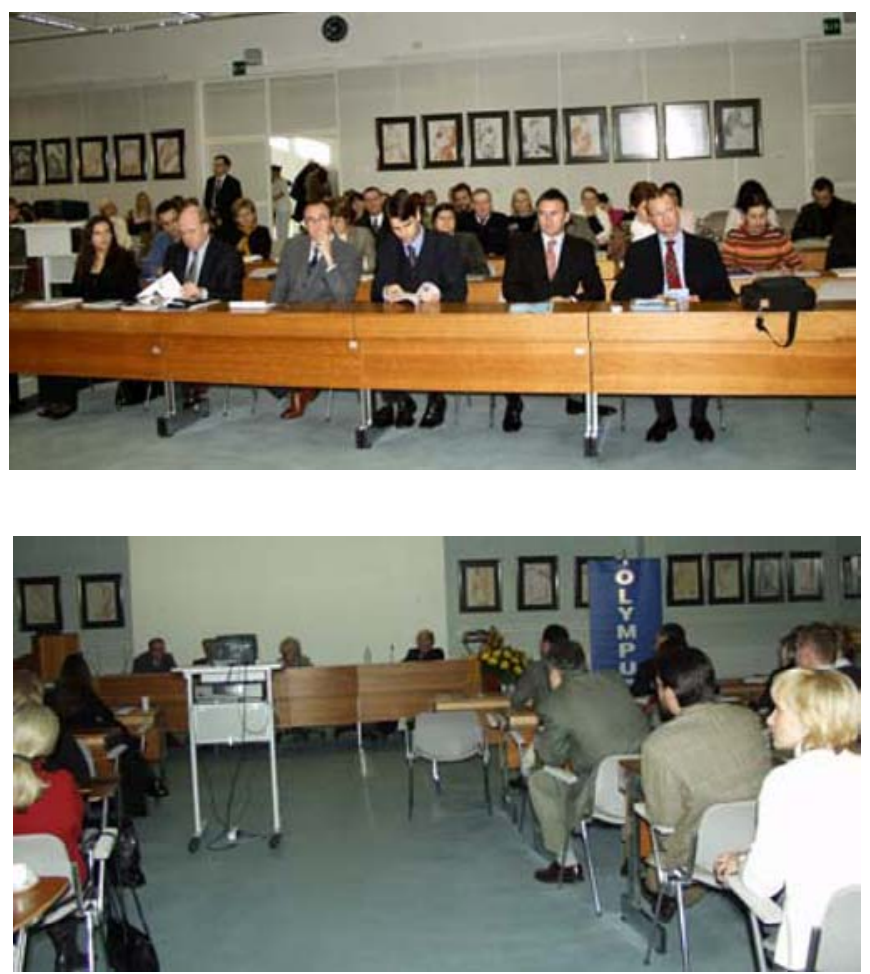

The auditory 


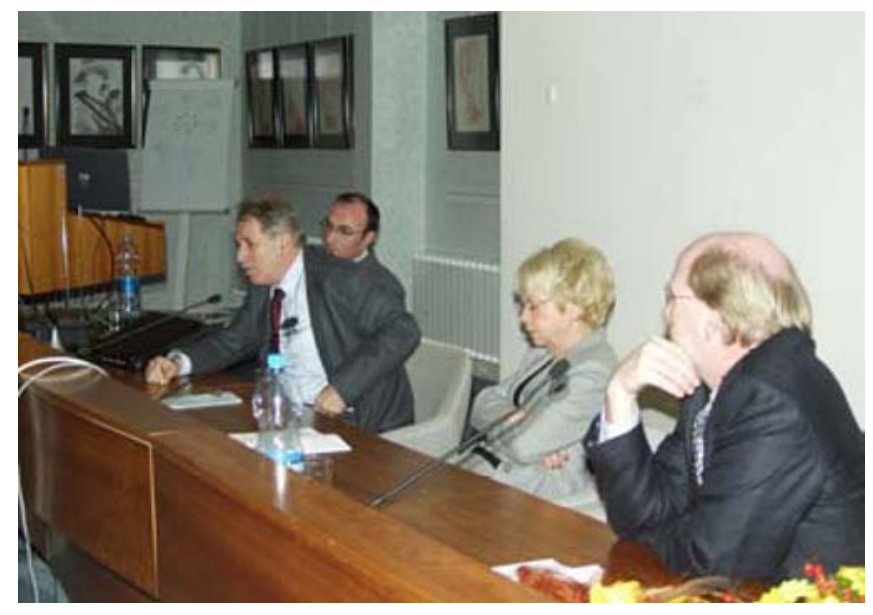

From left to right: Dr. Milan Reljic, Dr. Tomaž Tomaževic, Dr. RibicPucelj, Dr. Mark Hans Emanuel

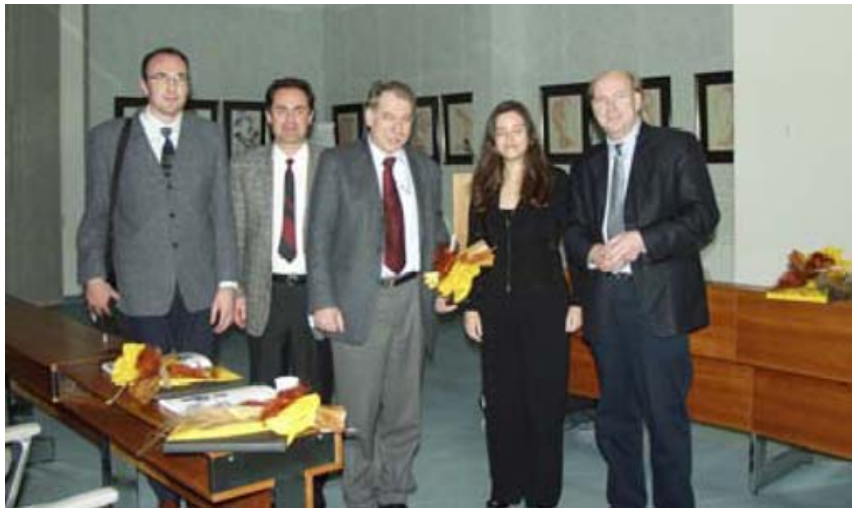

From left to right: Dr. Milan Reljic, Dr. Iztok Takac, Dr. Tomaž Tomaževic, Dr. Branka Žegura, Dr. Mark Hans Emanuel

my talk I presented our first results from the work in our outpatient hysteroscopy office. The hysteroscopic outpatient approach to the treatment of uterine pathology is new in Slovenia, so I received a great deal of feedback from my colleagues. Operative hysteroscopy, on the other hand, has been very well established in Slovenia for many decades. Dr. Emanuel from the Netherlands shared with us his innovative technique for hysteroscopic morcellation of endometrial polyps and submucous myomas. In his other talk he presented the 10-year results of his team regarding hysteroscopic myomectomy. The first session concluded with the talk of Mr. Liebold, from Olympus, who presented the technique of transcervical resection in saline in Slovenia for the first time.

In the second session three talks were presented by opinion leaders in Slovenian hysteroscopy and excellent teachers. Dr. Ribic-Pucelj from Ljubljana presented a review of information on which uterine anomalies should be treated. Dr. Tomaževic from Ljubljana delivered his talk regarding the unanswered question about the influence of small uterine septum on pregnancy outcome. Dr. Reljic from Maribor concluded our symposium with his presentation about the influence of hysteroscopic metroplasty on reproductive outcome in women with septate uterus.

The discussion at the end of the symposium was productive, and great interest was shown in hysteroscopy in Slovenia. The positive response of our participants on the symposium gives me energy to continue my work in promoting hysteroscopy in the spirit of ESGE.

\section{Branka Žegura}

Department of Gynaecology and Obstetrics, University Hospital of Maribor, Croatia

\section{ESGE Calender}

14th Annual Congress of the ESGE

Advanced Minimal Invasive Surgery: in the theatre and in the office

Athens, Greece, 6-8 October 2005

Info: esge@ctw-congress.de

www.ctw-congress.de/esge

\section{ESGE organised events}

At the occasion of the

19th European Congress on Obstetrics

and Gynaecology (EBCOG Congress)

Turin, Italy, 5-8 April 2006

Info: www.ebcog2006.it

ESGE Hand-on Training Session

Laparoscopic skill evaluation

Co-ordinator: R. Campo (B)

6-7 April 2006

Info: eage@esge.org

Special Symposium on Endoscopic Surgery

Current Place of Endoscopy in Gynaecological

Surgery

In collaboration with: J. Dequesne (ESGE President)

Date to be confirmed

Info: centraloffice@esge.org

\section{Events organised by National Societies or others}

State of the art myoma treatment

1 July 2005 (Amsterdam, The Netherlands)

Info: WINGS.MICHAEL@WXS.NL

Society of Gynecological Surgery in Finland

National Congress

22-23 September 2005 (Helsinki, Finland)

Info: paivi.harkki@fimnet.fi

Section of Gynaecological Endoscopy of the Czech Gynaecological and Obstetrical Society 
Congress: Endoscopy in Full View

22-24 September 2005

(Hradec Králové, Czech Republic)

Info: eim@nemvy.cz

www.laparoscope.cz/2005

The Dublin Laparoscopy Training Project

24 Sept 2005 - April 2006 (8 months)

Coombe Hospital, Dublin 8, Ireland

Info: fkavanagh@rcsi.ie

Serbian Society for Gynaecological Endoscopy (SSGE)

First Symposium on Gynaecological Endoscopy

29-30 September 2005

(Novi Sad, Serbia and

Montenegro)

Info: pjevicam@EUnet.yu

ETC - European Training Center for Gynecologic Endoscopy

Workshop Laparoscopy (myoma, endometriosis)

29-30 September 2005 (Saarbrücken, Germany)

Info: etc.saarbruecken@t-online.de

www.etc-gyn.de

ETC - European Training Center for Gynecologic Endoscopy

Workshop Hysterectomy

10-11 November 2005 (Saarbrücken, Germany)

Info: etc.saarbruecken@t-online.de

www.etc-gyn.de
TVS/Hysteroscopy in the office

15 November 2005 (Tallaght Hospital, Dublin, Ireland)

Info: fkavanagh@rcsi.ie

Flemish Society of Obstetrics and Gynaecology

(VVOG, Belgium)

National Congress

17-19 November 2005 (Gent, Belgium)

Info: vvog@online.be

AGE

2. Congress of the Forum Operative Gynäkologie (FOG)

17-19 November 2005 (Berlin, Germany)

Info: info@aakongress.de

www.aakongress.de

Endoscopy courses for Gynaecologists

25-26 November 2005 (Brussels, Belgium)

Info: donnez@gyne.ucl.ac.be

Laparoscopic Adnexectomy Course

19-20 January 2006

(Belfast, Royal Victoria Hospital, Northern Ireland)

Info: david.hunter@royalhospitals.n-i.nhs.uk 


\section{MEMBERSHIP FORM 2005}

Join (or renew) the ESGE as a member for the year 2005 by completing and returning this form as mentioned below (full information on www.ESGE.org)

PERSONAL DETAILS

Last name (family name):

First name :

Title :

Institute :

Department :

Street :

Postal code and city :

Country :

Email address :

PAYMENT SECTION (please tick the appropriate check-box):

Amount due in euro: If no amount is indicated, 100 euro will be charged

O Euro 30 Trainees (please prove by document)

O Euro 60 If you are a member of an ESGE Member National Endoscopic Society^ fromCroatia, Czech Rep., Slovenia, Sociedad Ibero-

O Euro 100 All other members Americana, Turkey, Hungary, Poland, Russia (please prove by document)

O Please charge my credit card: O Eurocard/Mastercard O VISA Card $\mathrm{N}^{\circ}$ :

Exp. date:

Name of Cardholder:

Signature:

O I enclose a certified bank cheque, payable to ESGE

O I will make a bank transfer in EURO to account N (IBAN) BE74 310126334607 of the ESGE. Bank : ING, SWIFT code: BBRUBEBB (bank address: ING Belgium, Markt 5, B 3200 Aarschot, Belgium). No costs for the beneficiary

Please Fax/Send completed form to: 